\title{
Contact calls: Twitter as a dialogic social and linguistic practice
}

\author{
Julia Gillen and Guy Merchant
}

This is a postprint version of the following article: Gillen, J \& Merchant, G. (2013), Contact calls: Twitter as a dialogic social and linguistic practice. Language Sciences, 35, 4758, http://dx.doi.org/10.1016/j.langsci.2012.04.015. This article may be used for noncommercial purposes in accordance with Elsevier's Terms and Conditions for Author Accepted Manuscripts.

\section{Abstract}

The rapid adoption of new forms of digital communication is now attracting the attention of researchers from a wide range of disciplines in the social sciences. In the landscape of social media, the microblogging application Twitter has rapidly become an accepted feature of everyday life with a broad appeal., This paper, from a dual autoethnography (Davies and Merchant, 2007) over one year, is a reflexive account of the experience of two academic Twitter users. We offer analyses of the functionalities of the semiotic environment and trace how our meaning making practices illuminate Bakhtinian (1986) principles of human communication, while at the same time constituting literacies that are distinctively new in character. We show how communication using Web 2.0 technologies 
can be described as semiotic and sociolinguistic practice and offer an appropriately dialogic and exploratory methodology to the study of new literacies.

Keywords

Bakhtin; dialogue; literacies; new literacies; new literacy studies; reading; social networking; Twitter; writing

\section{Introduction: an exploration of Twitter}

Twitter is, as we write, a fashionable social practice, and a media darling, simultaneously attracting amusement, fascination, opprobrium and ridicule (Arceneaux and Schmitz Weiss, 2010; Zappavigna, 2012). In the USA and the UK, the limited locations for our investigations in this paper, Twitter is currently achieving a new level of institutionalisation as it features in legal cases, debates about privacy, and political intrigue. It is, like the social networking site Facebook, a commercial success, a triumph of marketing that was fortunate in striking a complementary note with other applications, software and hardware innovations, so that it quickly captured the public imagination. In the first few years after its launch in 2006 it spawned more than 50.000 third-party applications (Potts and Jones, 2011). The microblogging tool Twitter is in some ways a "conversation" - at once democratic, in that everybody can join, ostensibly on equal footing, and a powerful, way of communicating one's message in an age of "networked individualism" (Wellman, 2001). It 
will not, we think, be difficult to argue that "tweeting" is a significant social practice worthy of attention: even if some people wholly shun participation themselves, they will, in a variety of contexts, have become aware that Twitter is impinging on many areas of life that touch upon the mass media. The use of Twitter is clearly more than peripheral in diverse social spheres, including revolutionary movements, the dalliances of celebrities, government, industrial disputes and international sporting events (Attia et al., 2011; Cottle, 2011; Zappavigna, 2012).

During the year that this study took place the use of Twitter moved from the so-called "Twitterati" - to use the slightly denigrating, yet paradoxically admiring term to denote users (if our reading of the connotations of "glitterati" holds water) to much broader participation. This paper is the fruit of an exploratory dialogue about Twitter, drawing on and developing a New Literacies Studies perspective. We wish to use this space to present the results of a dialogue between two autoethnographic investigations of Twitter, undertaken during the space of one year, between May 2010 and May 2011. We have two intermingled purposes here. The first is to present an exploration of Twitter as a social, linguistic practice, and our second is to consider Twitter in the light of evolving our ideas about how communication using Web 2.0 technologies can best be described.

Even in its short lifetime, the provenance and definition of the term Web 2.0, has generated a lot of debate (Merchant, 2009), but here we use it simply to capture the essence of widespread engagement with social media, a phenomenon that been described in terms of "new kinds of interactivity" and as a "second wave of enthusiasm for the internet in the 
popular imagination," (Merchant, 2009, p. 108). Out of this "second wave", we have seen the emergence of new techno-social practices - practices which often blur the boundaries between the public and the private, the personal and the impersonal, as well as presence and absence (see Sheller, 2004). Twitter does not stand alone as a highly interactive and public online discussion, but we contend that its simplicity, in terms of design and access, together with the communicative practices that have developed around it, make it a strong contemporary example of the dialogic.

The initial stimulus for research dialogue was created by conversations about Twitter when attending the American Educational Research Association (AERA) conference together at May 2010. We quickly discovered that although we were both using Twitter, for similar or at least overlapping purposes, and with similar and overlapping Twitter contacts, that actually our practices with it varied considerably in detail - and that these details were not trivial. Indeed, between the period of writing the paper and publication, Twitter and the practices and materialities associated with it, as well as our own individual practices have continued to evolve or mutate -a familiar characteristic of Web 2.0 technologies (Davies and Merchant, 2009). Our differences were indicative, for example, of different reading paths and authorship practices. Accordingly, we decided to each collect data about our own Twitter practices. At five meetings, the first in May 2010 and the last in May 2011, at the next AERA meeting, we compared and discussed our understandings and uses of Twitter, working from the most specific details of screenshots to theoretical understandings, and back again. 
We were keen to test out how communication using Web 2.0 technologies could be understood by applying our already existing theoretical notions about language and communication. In particular, we were interested in the extent those theoretical understandings might need to adapt or evolve in response to the new economy of communication. The relationship between our reflexive study of linguistic practices on Twitter and our theoretical understandings of communication are intermingled as we have adopted a "logic of inquiry" (Green, Dixon and Zaharlick, 2003), an approach to research that is coherent across theory, praxis and method. Accordingly, a dialogic understanding permeates this work, being the source for our presuppositions about language, as understood within a Bakhtinian frame. Our methodology in working towards the production of this paper and for providing a frame for looking at Twitter turns out to be a more complex and interesting phenomenon than at first sight.

The dual auto-ethnographic approach has two key features each of which present important opportunities and limitations. First, a dual auto-ethnographic approach relies (only) on examinations of our own experience, as refracted through the reflections and experiences of each other. This has led us to achieve the insights and comparisons presented in this paper. Negotiating the narrative voice of the account adds a further layer of complexity, but one that is quite consistent with our Bakhtinian stance. Second, our dataset has comprised a series of discussions based on screenshots of each others' Twitter streams. contextualised through lengthy discussions. A single screenshot has been the basis for considerable reflection, debate and subsequent collaborative writing. This process is very different from constructing a 
framework for analysing every instance of a dataset and then applying an analysis of content, network, or some other aspect that is essentially extrapolated from the context of use. Such analyses are extremely useful (see e.g. Barnes and Böhringer. 2009; Zappavigna, 2011; 2012) but our purpose here is otherwise. In accordance with the useful discussions of intersection between methodology and theory in this area by authors like Georgakopoulou (2006) and Thurlow and Mroczek (2011b), we have used a different approach from that of computer-mediated discourse analysis (Herring, 2004), essentially a variationist approach that aims at a certain kind of completeness with a specific dataset. We have not conducted formal interviews and surveys of other users or used other measures to achieve "objectivity", but consider our approach as ultimately complementary to a diverse range of approaches to the study of new media, particularly related to practice-centred approaches to the study of new media such as by Lee (2011); or the discourse-ethnographic approach of Androutsopolous, (2010; 2011). So ours is an interpersonal, partial viewpoint with all the advantages and disadvantages that entails. However, situated acts of interpretation are always involved in communication (Rommetveit, 1992; Scollon, 2001); we hope therefore that this account will become part of the researched picture of the Twitter phenomenon that interests a growing number of academics at the present time (e.g. Gruzd et al., 2011; Java et al., 2007 Marwick and boyd, 2011; Zappavigna, 2011). We hope that it also complements analyses of the discourses and practices of digital technologies such as those in recent and influential collections (e.g. Androutsopolous, 2006; Danet and Herring, 2007; Thurlow and Mroczek, 2011a).

6 


\section{Twitter and the study of literacies}

We use Twitter to explore some theoretical issues about the investigation of language in general, making use of what is sometimes disparagingly seen as one of the most frivolous and ephemeral ${ }^{1}$ channels of language use today, to situate our study in a sociohistorical frame of reference in the study of language. We will demonstrate that Twitter is a complex phenomenon and one that demands to be viewed as the "virtual" instantiated in the "material" (Hayles, 1999; Gillen and Merchant, in press), and one that takes on a different materiality with each subsequent reading. Studying Twitter has illuminated our understandings of communication; communication as an activity that is characterised by instability of meaning, and potential and/or actualised creativity emerging through innovation in everyday accessible practices - as opposed to more privileged literacies. This is an exploratory paper, a piece of work tentatively advanced into the interdisciplinary terrain of (new) literacy studies (or studies of new literacies).

First however, the issues alluded to by the parentheses in the last sentence need some unpacking. Our shared interest in issues of purpose, identity performance, socio-technical practices and materiality means that we locate ourselves within the established and developing fields that are labelled as Literacy Studies, New Literacy Studies, New Literacies, Web 2.0, and Digital Literacies. Perhaps a useful starting point here is to distinguish between (New) literacy studies and new literacies. (New) literacy studies (NLS) pay attention to the 
circumstances in which texts come into being, identifying literacy practices as existing within complex chains of communication, often involving talk around texts, references to previous texts and so on. There is a reason why we place the "new" in parentheses here, as, somewhat confusingly, there are two terms we need to refer to, each of which are currently in a period of evolution. New Literacy Studies (NLS) is a term that has for nearly thirty years now been used to apply to a holistic or ecological approach to literacy (Barton, 2007) ${ }^{2}$. In key works published in the early 1980s, Shirley Brice Heath in the North Carolinas and Brian Street in Iran took ethnographic approaches to the study of literacy as practiced in different circumstances by people in various settings in the communities in which they lived, uncovering a rich array of practices and understandings of literacy (Heath, 1983; Street, 1984). Of course these works were themselves situated in rich traditions in terms of method, approach and understandings of literacy, but they also offered creative innovations in methodology and insight; the point to make here is that they are now seen as foundational in NLS. Working in diverse settings, writers such as these and many later scholars provided powerful arguments for seeing that literacy as a set of discrete skills in reading and writing one predominantly associated with formal education - is an impoverished view that occludes the diversity and complexity of the practices that people learn and use in accordance with their purposes related to specific settings and needs. In other words, as Bazerman suggests it is a mistake to attempt to isolate the practice of literacy from its surrounding context. 
Because the sociality of texts is often a matter of implicit social understanding embedded in our recognition of genres that shape communicative activity, reading and writing have regularly been mistaken as autonomous processes of pure form and meaning, separate from social circumstances, relationships and actions. (Bazerman, 1999, p. 27).

Along with this development of the NLS approach, there has been a growing interest in the ways in which everyday literacies are themselves evolving. And so the work on new literacies (Lankshear and Knobel, 2011) has traced the complex evolutionary path of textual production and distribution that has emerged over the last decade and particularly, although not exclusively, those associated with Web 2.0 technologies $^{3}$. Those working in this field describe the rapidly multiplying intertextualities that thread across modes and genres, as people take up semiotic resources in one place and reshape them to fit their purposes in other domains. Although strongly associated with the digital literacies, new literacies are not necessarily online but yet are united by the cultural logic of contemporary practice with its emphasis on collaborative creativity and re-mixing (Davies and Merchant, 2009).

An important effect of these two approaches and their emphasis upon the local, situated qualities of semiotic resources as they are taken up in practice is a commensurate move away from an approach to analysis that assumes that objectivity is possible. Analyses that confine themselves to texts necessarily assume, at least to some degree, that meaning is fixed and that access to meaning by a kind of omniscient researcher is possible. It is no accident that this 
kind of approach is more often practised with durable, even canonical texts that can attract a shared community of interpretation and understanding around them. The more fluid textual formations that are associated with new literacies constantly resist the application of these rubrics. Yet in fact any text, including the most long-lived and also the most local and ephemeral can, on the contrary, be regarded within a Bakhtinian framework as always unstable, the fruit of a temporary shaky and partial bridge of understanding between author or speaker, and reader or listener. All communications, whether written or oral, can be best understood as social interaction, not actually possessing an intrinsic, fixed meaning, but alive and meaningful through animation in dialogue: "A word is a bridge thrown between myself and another" (Volosinov, 1995, p. 130).

In keeping with this line of thought, we will present some exemplars of analysis, examining some Twitter texts as collected by us, whilst at the same time considering the technologies that enabled and constrained those presentations. Drawing on Barton (2007), we conceptualise Twitter texts as part of discrete literacy events, and as an instantiation of the practices in which they are embedded. Those events will be shown to be part of practices, not merely understood as a string of events, but as practices that evolved as our own purposes changed, as the Twitter technologies evolved, and as social reception of Twitter adapted to its growing popularity and so on. Finally, in conclusion, we will consider how this exercise might relate to and have influence on the dialogic frameworks of language and literacies that we began with. 


\section{Making sense of Twitter}

\subsection{Initial description}

Our first analytic challenge is to provide some sort of description of Twitter that helps us to conceptualise it as a textual space. This is not as straightforward as it may seem, firstly because microblogging does require a basic understanding of online environments and secondly because Twitter has spawned a multitude of related applications that enable users to view and send tweets in different forms (such as Tweetdeck) and on different devices (such as UberTwitter for Blackberry smartphones). To simplify matters we assume that readers are reasonably familiar with some online environments and so will not attempt to describe terms such as navigation, tagging, and posting. We will begin by examining the desk-top version of Twitter as we knew it in the Summer of 2010. 


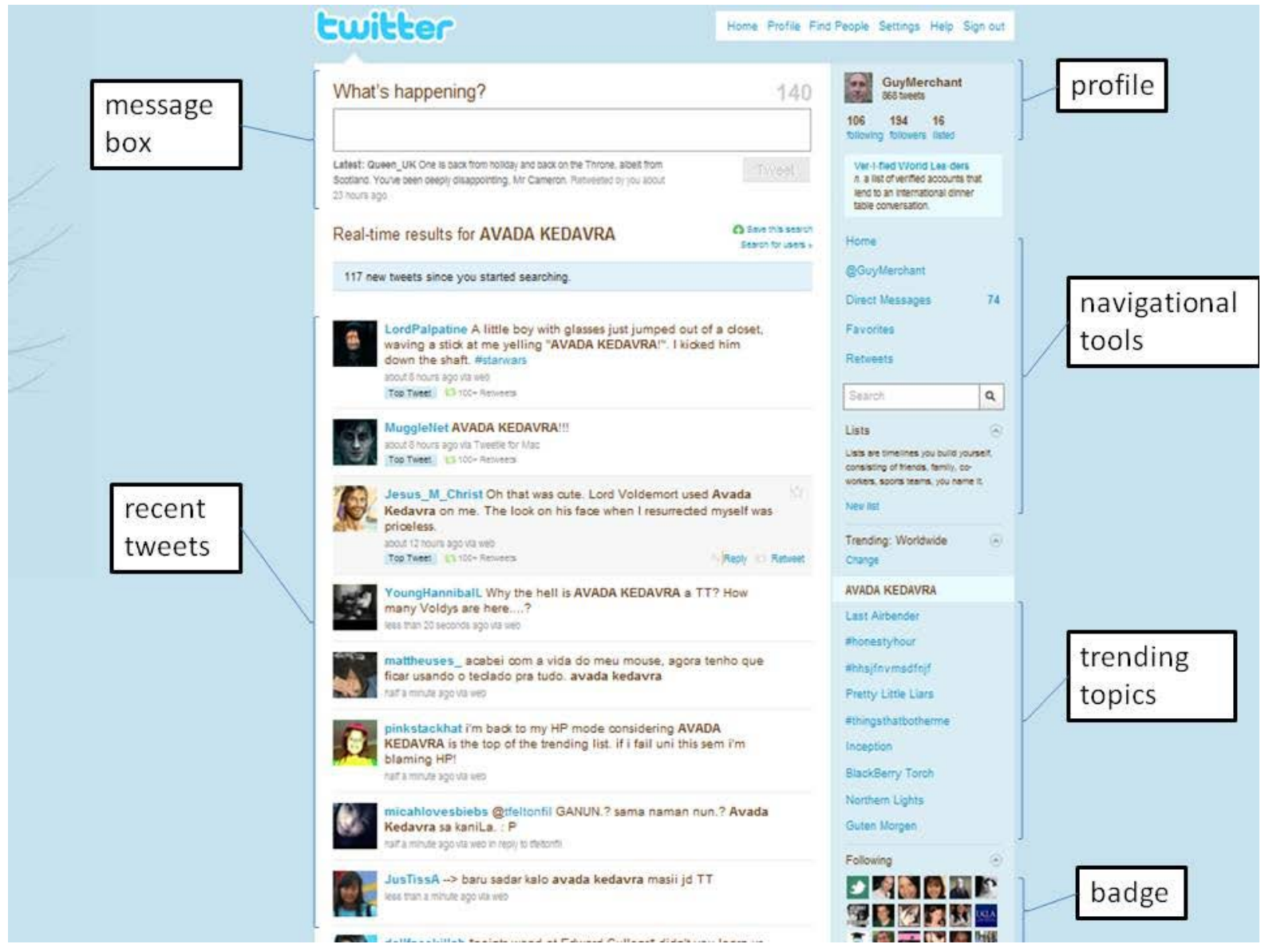

Figure 1. Screenshot of a Trending Topic on the desktop version of Twitter captured by Guy Merchant in August, 2010.

The annotated screenshot in Figure 1 shows an example of a page from Guy's viewpoint selected by him as more or less typical or representative of his desktop view of Twitter in Summer 2010. At this time, he was becoming more engaged with Twitter on the small screen of a smartphone, but this screenshot was shared and worked on together as exemplifying a desktop view that in practice informed most of our readings. 
We use this to provide a basic analysis of some functionalities and features of the desktop appearance. As can readily be seen, Twitter is a screen-based text, its design is multimodal, built up from "modules", or sub-textual units, familiar from other web spaces (see Kress, 2010a). Table 1 shows an analysis of a Twitter screenshot that identifies some of the salient design modules. These are then categorised and glossed in Figure 2. It must though be re-emphasised that this is an analysis of the Twitter interface of Summer 2010; some features have subsequently been modified.

Table 1

Categorising Design Modules on the Desktop Version of Twitter (August 2010)

\begin{tabular}{|c|c|c|}
\hline Design modules & Categories & Twitter features \\
\hline message actions & Different kinds of & \multicolumn{1}{|c|}{ Tweet - a message that can be read } \\
messages & $\begin{array}{l}\text { by all. } \\
\text { Re-tweet - a message from a third } \\
\text { party which you "repeat". } \\
\end{array}$ & $\begin{array}{l}\text { Reply - a response message which } \\
\text { refers to a third party comment using the @ } \\
\end{array}$ \\
& convention. \\
\hline
\end{tabular}




\begin{tabular}{|c|c|c|}
\hline & & $\begin{array}{l}\text { Direct message (DM) - a private } \\
\text { message. }\end{array}$ \\
\hline $\begin{array}{l}\text { message } \\
\text { Conventions }\end{array}$ & In-message items & $\begin{array}{l}\text { @convention - prefixing a Twitter } \\
\text { user's name with "@" hyperlinks to that } \\
\text { user’s home page so on Twitter we are } \\
\text { referred to as "@JuliaGillen" and } \\
\text { "@GuyMerchant". } \\
\text { \#convention - using the hash symbol } \\
\text { "\#" as a prefix to a category creates a } \\
\text { "hashtag" which is a way of pooling tweets } \\
\text { in that category, that are then searchable. } \\
\text { Eg: conference tweets might include } \\
\text { "\#lutwit13" or "\#virt10" to create a cluster } \\
\text { of tweets. } \\
\text { constraint, most people use a 'link- } \\
\text { shortener' like Bitly or Tinyurl to save } \\
\text { webpan be used to refer tweets to other } \\
\text { characters. Eg: the web address }\end{array}$ \\
\hline
\end{tabular}




\begin{tabular}{|c|c|c|}
\hline & & $\begin{array}{l}\text { http://myvedana.blogspot.com/ becomes } \\
\text { http://bit.ly/9xDNUT using bit.ly, saving } 9 \\
\text { (valuable) characters. }\end{array}$ \\
\hline other elements & $\begin{array}{l}\text { Data shown on the } \\
\text { home-page of the basic } \\
\text { desk-top version }\end{array}$ & $\begin{array}{l}\text { Profile - picture/avatar or other } \\
\text { personal identify with basic metrics (total } \\
\text { number of tweets, number of followers, } \\
\text { number followed, number of times listed). } \\
\text { Navigational tools - links to home- } \\
\text { page; listings of: favourites; mentions (eg: } \\
\text { of @JuliaGillen); direct messages; } \\
\text { retweets; groups (lists). } \\
\text { Trending topics - the most popular } \\
\text { topics of the moment (these often contain } \\
\text { messages that have been retweeted over } \\
100 \text { times). } \\
\text { Follower badge - a composite of the } \\
\text { pictures/avatars of your followers. }\end{array}$ \\
\hline
\end{tabular}

As can be seen, the individual's home page or Twitter stream is quintessentially a product of the digital age. It is an individual or personalised portal in the "Twittersphere". 
Running in real time, it is web-based, personalised, and multimodal, and as we have seen is available on desktop computers as well as on a range of mobile devices. It is also simultaneously consumed and produced , constituting a dynamic illustration of how literacy practices are reconfigured in new times (Kress, 2010a). We read and write individual tweets and they are hardly ever printed out (at least we never printed any until working on this paper!) and in this sense they are ephemeral, existing only and very briefly on the screen, unless they are "re-tweeted" Tweets are material in the sense that they take an appearance on the screen of our smartphone, iPad or desktop computer and in the way in which our own contribution depends upon keying ${ }^{4}$ in letters and spaces that constitute our own utterance. Yet they have a digitalised or virtual existence which means that in each reappearance on followers' screens,they are recontextualised and thus take on a new appearance.

It is this feature of some online environments that means that reading genuinely is a different act from that associated with traditional texts, for the text itself is rendered differently in terms of the semiotic resources that constitute and surround it, for each reader. So, although each person's reading of any text is different - this is a well known theme in reader response theory (see Iser, 1971) - in the digital environment the text itself is mutable. Thus, an analysis of an utterance in Twitter ought, for some purposes at least, to take into consideration its context. We will return to this point below.

\subsection{Point of view, addressivity and conversational coherence}


An important feature of the Twitter environment is the individual user's ability to choose who to attend to: whose tweets to read and whose to filter out. An individual Twitter account allows one to search for and select others to "follow", and this selection determines whose tweets show up on your home page. This gives the individual a personal point of view and a social network of people that are "followed" and over time, partly as a result of reciprocity, a group of "followers". This concept of "following" is shared with a number of other social networking sites, although an important distinction must be made between those such as Facebook that constrain this relationship to one of symmetry, as opposed to Twitter's inherent asymmetry. We find the use of the term "following" interesting in itself, because it avoids users having to specify the selection of friends - a problematic concept in this sort of environment - whilst still embracing an ethos of social preference and popularity. Two connotations of following make it a useful description: 1 . Following [v] as suggesting movement, pursuit, and passage through time, and 2. Following [n] as used to describe a group of supporters or fans (those, for example, who follow a particular team in sport). In the Twitter pursuit the dialogic is in-built in the way that we are cast as both the followers and the followed. But this relationship is inherently unstable and allows for constant modification as we may lose interest in who we are following, follow others, and in turn lose followers ourselves as they lose interest in us. In this sense, microblogging embodies a kind of postmodern fluidity of relationship.

Yet against this fluidity, the principle of following helps to establish a sense of audience in Twitter and so the selections, the choices of who to follow, that are described 
above work to establish a sense of addressivity (readership) which in its turn allows for some sorts of coherence and hence meaning. In his discussion of speech genres, Bakhtin argues: ...addressivity, the quality of turning to someone, is a constitutive feature of the utterance; without it the utterance does not and cannot exist. The various typical forms this addressivity assumes and the various concepts of the addressee are constitutive, definitive features of various speech genres. (Bakhtin, 1986, p. 99.)

Addressivity in Twitter works on a number of different levels. At the most fundamental level one who subscribes to Twitter is invited to respond to the deceptively simple prompt question "What's happening?" using the 140 characters available (a reminder is shown on the upper right hand side which adjusts, tallying the characters as you type). As Lee (2011) has shown, the precise wording of this prompt, which as in other microblogging environments, occasionally changes, is an important aspect of the design that has a strong influence on people's choices of how to respond.

\section{What's happening?}

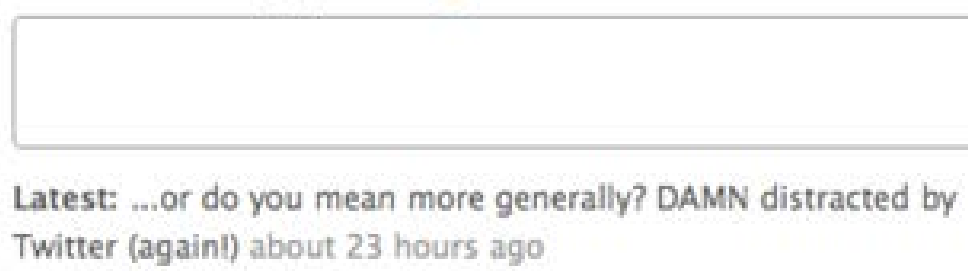

Figure 2: Prompt question and surrounding text on the desktop version of Twitter

(August 2nd, 2010) 
As the screen segment (or design module) shown in Figure 2 shows, this section also displays your latest tweet - in this case: "...or do you mean more generally? DAMN distracted by Twitter (again)", and on the lower right the "Tweet" button which one clicks in order to publish. From the perspective of addressivity there are a number of complications already. Although we have said that the prompt question is provided by the authors, or owners of the site - and there is an objective truth in this statement - it must be assumed by the knowledgeable user, that the response is actually directed to the Twittersphere in general (in the sense that tweets are public), but more specifically to one's own followers. Addressivity in the sense of "turning to someone" is in fact only prompted by the site; in tweeting one must imagine a wider audience albeit an audience who may or may not have paid attention to one's previous tweet.

Of course a problem with starting with this particular screen segment is that it automatically isolates the individual message, as utterance, from the ongoing flow of conversation. Perhaps it is only newbies who attend to the "What's happening?" prompt. We suggest that more experienced Twitter users are likely to ignore the prompt and input a message of their choice, or one that is a direct response to a previous message. A core question that our initial study raises is how individual users establish some sort of communicational order to avoid their Twitter stream becoming an incomprehensible cacophony of utterances. At this point we are able to identify a number of ways that some sort of order is established 1) by Twitter itself and 2) by individual choices within Twitter. 
Firstly, the way in which Twitter is designed provides some basic structural constraints (for example: the character limit; the sequential display of tweets; the regular refresh; and the visual separation of tweets) that simplify the flow of messages. These structural constraints help to bound the individual contributions, but on their own they are not sufficient to produce communicational order. However, some of the other common actions offered by Twitter, such as direct messages, replies and retweets are conducive to more organised interchanges. Direct messages (DMs) are person-to-person interactions that tend to invite more cohesive and coherent message exchange, whereas replies and re-tweets offer a contextual backdrop for new tweets. Secondly, user conventions such as the use of the @ prefix to refer to a Twitter user is used as a reference and hashtags (\#) are used to categorise tweets by topic or event. So for example Guy would regularly use event hashtags, such as "\#aera2010", referring to the American Educational Research Association Annual Meeting, 2010, to signal the conversational context of his tweets as well as referring to colleagues and presenters with a Twitter presence using the prefix (eg At session with @JuliaGillen).

As Crystal (2001) has observed, entering a multi-party online environment such as a forum may well resemble a cocktail party as opposed to a more everyday dyadic interaction in terms of conversational coherence. Honeycutt and Herring (2009) discuss how Twitter may be experienced as a "noisy" environment, with a constant flood of overheard nonsequiturs, with little relevance to the reader, or messages may appear as interwoven conversations. Figure 3 below displays a screenshot captured by Guy in August 2010. 


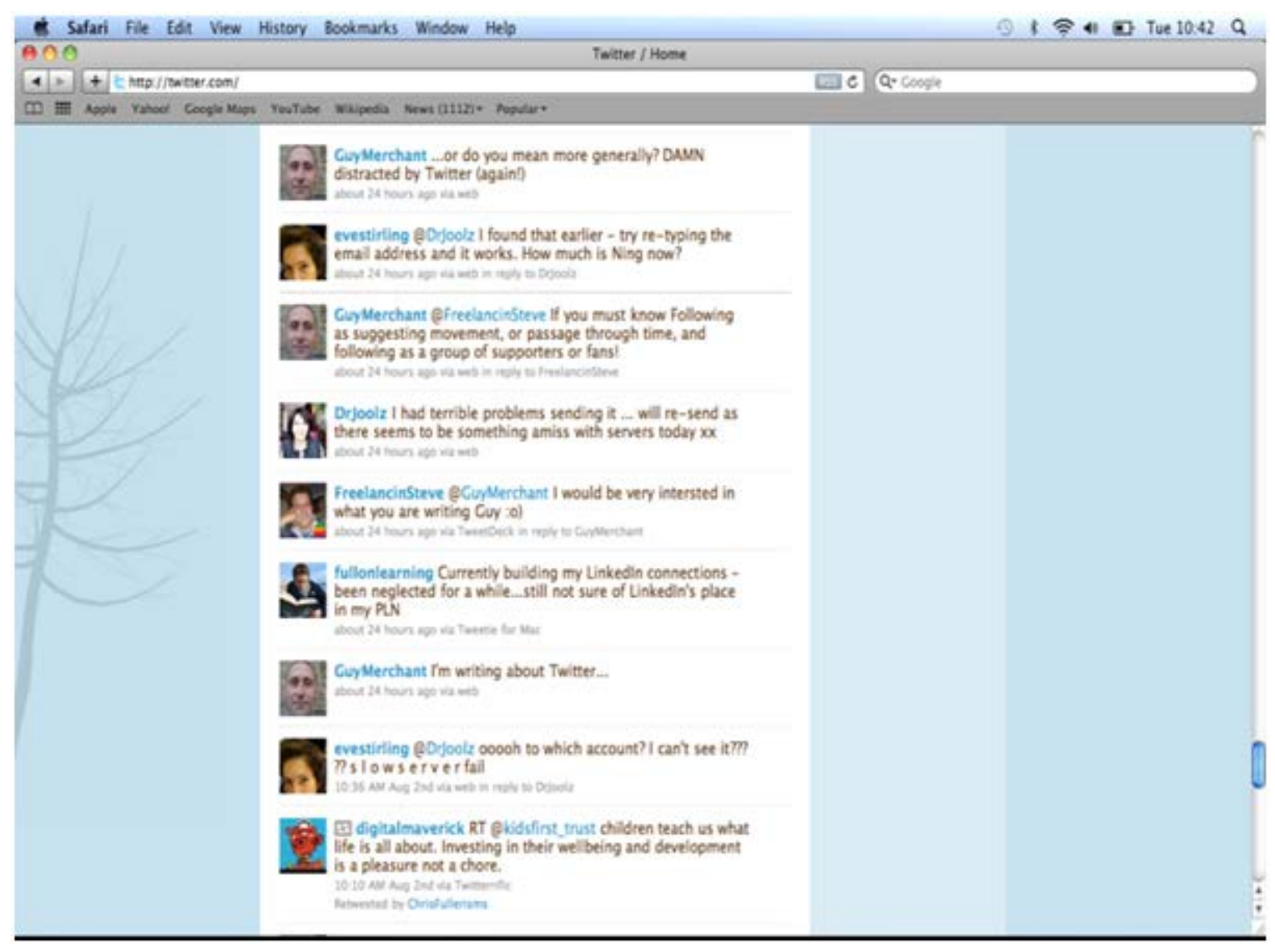

Figure 3: Screenshot displaying interwoven conversations (August 2010).

Figure 3 is at the same time a manifestation of a private understanding; this view can only have appeared on Guy's desktop view of Twitter in the form it takes above. Yet every individual posting is public in the sense that each of them was visible to a number of Twitter users. To another imagined Twitter user, each of these messages, if captured in a single screen shot, may well, if surrounded by a combination of unrelated messages as is very likely, have been read just like an overheard singular utterance at a cocktail party. In this specific 
site of engagement, "the real-time window that is opened through an intersection of social practices and meditational means (cultural tools)" (Scollon, 2001, p. 4) we can observe interwoven threads of two conversations, each seemingly at least revelatory of shifting attention to audience. Twitter views, as this one, are most effectively read from the bottom up, if sequencing and coherence are pertinent in a particular reading. Thus, from bottom to top in Figure 3 we have 9 messages. The bottom one, or earliest, is not responded to or picked up in this view; but it is nevertheless evident that it does have relation to at least two other tweets elsewhere, through its structure of double retweeting. The second message, by @evestirling ${ }^{5}$, appears with its exophoric reference and addressivity in "@DrJoolz" to be evidently part of a dialogue. Yet at the same time the graphological playfulness of the insertion of spaces in "s l o w s e r v e r" might, we cannot tell, be an element intended to entertain a broader audience, as indeed it did, while mainly attending to the concerns of the dyad. (We can note that @evestirling and @DrJoolz were not choosing a more private channel to write in). Above, we can see two more messages attuned to this primarily dyadic exchange. Interwoven with this, we can see how @GuyMerchant's posting: "I'm writing about Twitter...." was seemingly not directed to any specific individual but, rather, to whichever of his followers in general might pick that up. It is taken up with some enthusiasm by @FreelancinSteve who doubly emphasises that he is responding to that specific posting through use of the @ and Guy's first name. Operating with positive politeness (Brown and Levinson, 1987) in mirroring @FreelancinSteve's use of the @, Guy responds first very specifically, making maximum use of the available space, and then, shortly afterwards, makes 
another posting. In the posting shown at the top, Guy makes use of three dots.

Conventionally in Twitter this device indicates that the tweet is a continuation of an earlier tweet so that if wanting to know about the connection a reader knows s/he should modify the view so that the earlier posting/s by that individual are made visible. However, in this tweet, Guy is doing at least two things. He is orienting to @FreelancinSteve's question, by offering him the opportunity to ask for more information, and yet at the same time addressing a broader audience, including indeed himself as a reader, through a playful expostulation.

The example sequence shown in Figure 3 then is illustrative of the uniqueness of a specific Twitter user's view, the possibilities and by implication at least the constraints on conversational coherence and the interwoven practices of reading and writing. Kress, (2010b) claims that these amount to a revolution in communication and indeed if we compare such an interchange, in all its semiotic and interactional complexities, with any possible interaction prior to digital technologies, it is difficult to disagree. We have demonstrated how, despite all the possibilities for inchoate noise, we found instead in these examples a tendency towards constructing coherence.

We now turn to focus more specifically on reading, as again we will claim that there are both continuities in terms of links to theoretical understandings relating to language and communication in general, and some interesting innovations that may be associated with this communicative practice in general. 


\subsection{Reading and meaning-making}

Viewing is not passively receiving a text that somebody else has created. It is widely held that comprehension is the active construction of meaning. Stevenson's comment that: "All comprehension is creation" (Stevenson, [1879]2008) could well be applied to Twitter, which is an exemplary site for creative reading, and this is part of its appeal. The creative construction of meaning in Twitter is not simply about working on the meaning of individual tweets, it is about making conscious navigational decisions. One's reading path (Kress, 2003) is related to the literacy practices within which a specific text is engaged with. Figure 4 below is a screenshot taken by Julia to illustrate some features of a specific site of engagement centring on Twitter on 4 May, 2010. 


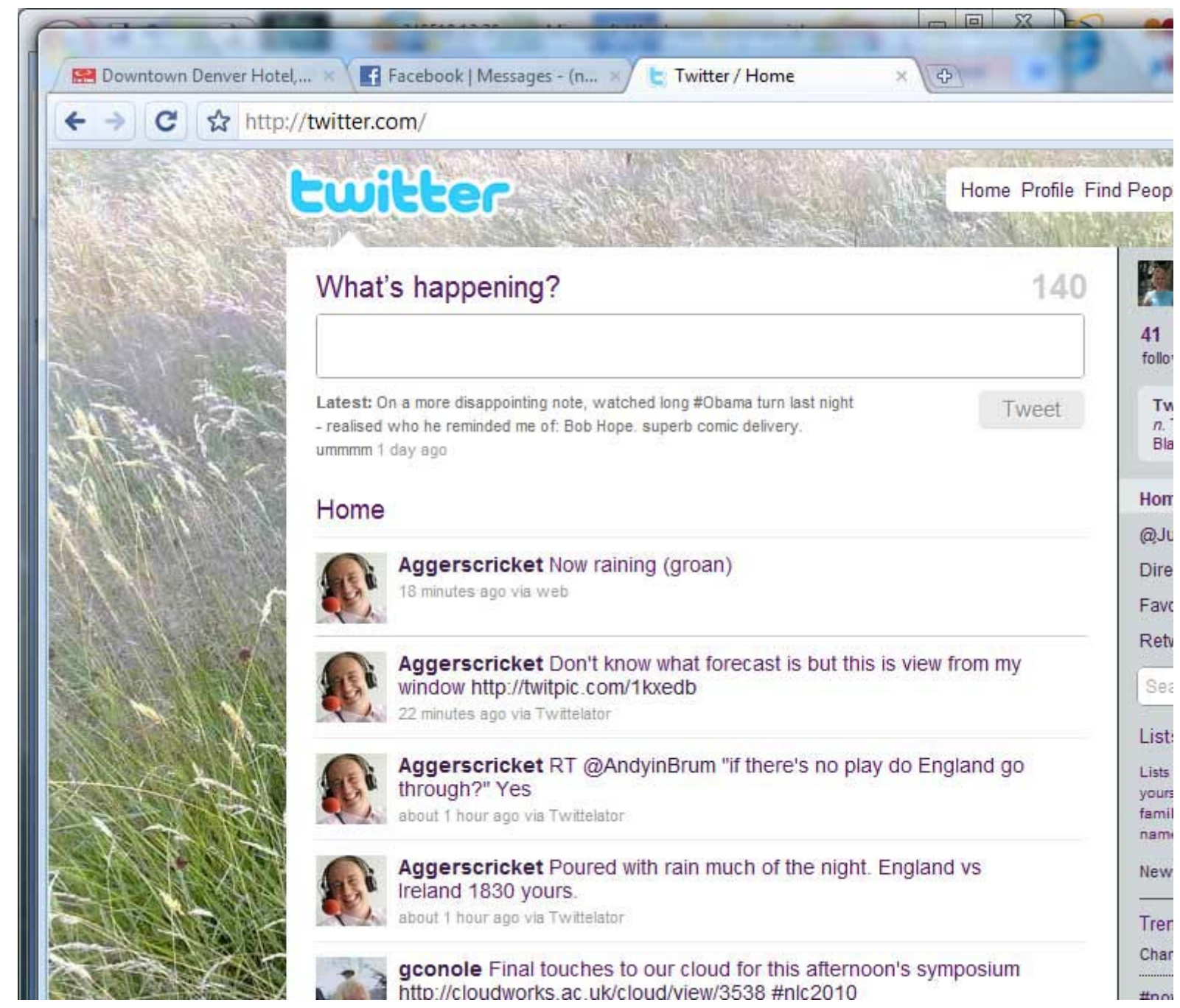

Figure 4: Screenshot: Bad weather for cricket (4 May, 2010).

NLS emphasises the context within which a particular act of reading is undertaken, and the way that this specific screenshot has been cropped - as have all the others - permits some understandings of the reading path to be retraced, and not others. 
The upper three browser tabs in Figure 4, indicate the trail of views that Julia took on $4^{\text {th }}$ May 2010 at midday, before alighting on this view of Twitter. First, she checked a Denver hotels website to ascertain the location of one of the conference hotels, then she looked at Facebook to respond to a message there, and then thirdly looked at Twitter. The selective view copied here illustrates the history of her reading path and her subsequent focus of attention. Julia occasionally follows interest hashtags but far more often takes a look at her home page and then selects from a range of potential actions, usually stemming from the immediate first few messages and generally disregarding everything on the right hand column (occluded in this view). One of her favourite tweeters is @Aggerscricket, a Twitter identity for a professional sports commentator, Jonathan Agnew of the BBC, a frequent poster. Julia will focus on these tweets at key moments for the England cricket team, since Agnew covers the team's fixtures at international cricket events. At the point in time captured here, the concern was whether a planned match would go ahead or not. The match was not due to start for some hours but @Aggerscricket is communicating his concerns that it might be disrupted by bad weather. At the time of reading this stream Julia was sufficiently interested - in part through previous experience of enjoying Agnew's photographs, which, like his tweets, she finds witty - to click on the link contained in the second message down. "Twitpic" is also the main application she uses if she wishes to include images in twitter messages. Below in Figure 5 is a screenshot of the Twitpic view of @Aggerscricket's photo: 


\section{twitpic}

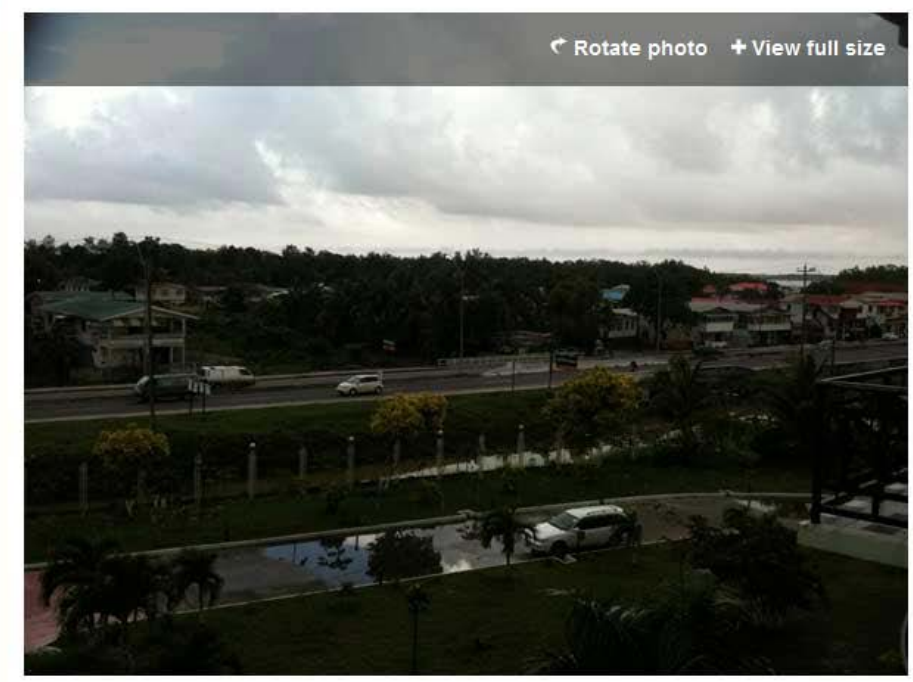

Don't know what forecast is but this is view from my window
Posted on May 4, 2010

by Aggerscricket

"There's gotta be a better way to save!"

There is. Discover Bank.

DISCOVER

More photos by Aggerscricket

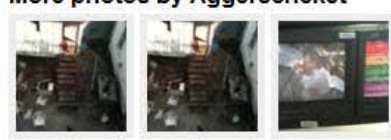

Put this photo on your website

Views 277

Figure 5: Bad weather screenshot on Twitpic (4 May, 2010).

Later in 2010 Twitter developed a way of showing the images in Twitter without having to click through to the Twitpic site, but at this point the separate action was needed. However the Twitter message is also included on the Twitpic page and so it is evident that, combined with the picture the message that could, if taken alone, - or perhaps in a stream of other twitter messages that rendered this particular one apart from the context of other @Aggerscricket tweets, highly ambiguous. @Aggerscricket will not of course know, when he posts a message, whether it will be read in the context of his messages sent before or since, or whether it will stand alone. In either event, it is likely to have a different effect. It may be 
read cumulatively, as here, where growing fears about the weather over the course of an hour have constructed a short narrative. Agnew has, in his four messages communicated the timing of the forthcoming planned commentary; given vivid evidence as to the likelihood of it being rained off (yet without referring to official sources of evidence as he is obliged to as a commentator during the hours of broadcasting on the radio); and additionally explained how this will affect the team's progress in the competition if this match does not happen. On the other hand, if a follower only reads one of the four tweets, owing to the others not appearing on screen - perhaps because they were crowded out by other tweets, that reader would still be able to understand the salient message, that, it is raining and therefore that the planned match is not likely to go ahead.

Any reading path then is intimately linked to a reader's purposes, both in the moment as instantiated by a particular path and more broadly, as we mentioned at the beginning, according to their valuing of Twitter, their choices of topics and/or people to follow. Finally, then we turn our attention to developing this topic of purposes.

\subsection{Purposes: Twitter as social practice}

As we mentioned above, our aim in designing this study was partly stimulated through early recognition of some diversity in purpose that we had not initially suspected. In dialogue we found that our uses of Twitter could be distinguished by purposes. In May 2010 one of Julia's purposes in reading her @JuliaGillen twitter stream was to keep up with cricket. She 
was also engaging with other Twitter streams through her other Twitter identities, for example@EVIIpc, an identity she had created in connection with another literacy studies project, one centring on Edwardian postcards (Gillen, 2011; Gillen and Hall, 2010). One of Guy's main purposes in using Twitter at AERA 2010 was to keep absent but very interested colleagues informed about the conference as it progressed.

In Summer 2010 in our dual auto-ethnography we identified these as some of the emerging practices for which Twitter was being used,:

citizen journalism

political activism

maintaining a fan-base

event back-channel

corporate advertising

service marketing

crowd-sourcing

informal social-networking

ambient sociability ${ }^{6}$

At this time we recognised that online communication and particularly the kinds of interaction associated with the so-called social media do not hold universal appeal. For example in researching for the book Web 2.0 for Schools Guy working with Julia Davies met many people whose reaction to social media could be summarised as "I just don't get it" those who for perfectly understandable reasons could not see the point of keeping a blog, 29 
uploading or commenting on a YouTube video, or becoming part of the Flickr photosharing community (Davies and Merchant, 2009). The same goes for Twitter, often criticised in such terms as "pointless babble" (cited by Baym, 2010, p. 30). Even those with some experience of Web 2.0 environments may take some time to understand its possibilities.

In April 2011 our purposes as users of Twitter had evolved somewhat. Julia was especially engaged at creating and using more Twitter identities as she revoiced Edwardian postcards, whereas Guy's were more focused on specific interest groups and events. Both of us were less interested in tweeting about the conference that marked the end of the period of study. We realised that one reason for this was that this practice had changed greatly within the span of a single year. In May 2010, tweeting about conferences was a "backchannel", an unofficial, unsanctioned creation of a small online community that evolved its own usergenerated hashtags for comment (McCarthy \& boyd, 2005). That in some way conference Tweeters perceived themselves as a community was evidenced by the meet-ups; some people who were tweeting at the conference thought that this practice gave them enough in common for an informal get-together to have some value. By April 2011 the conference organisation was attempting to institutionalise the Twitter practice, to bring it into the realm of official, sanctioned practice, just one of the many communicative practices associated with the event.

The official conference introduction to Twitter was somewhat clumsily introduced: eschewing any mention of what to experienced Twitter users would be the essential simple information of the hash tag in favour of a rather oddly worded introduction to the technology. P. 5 of the programme introduced Twitter under the headline "Technological innovations for 30 
2011 Annual Meeting AERA Program App and Twitter." We reproduce the notice in full in Figure 6 as we think the pairing of Twitter with the app as interesting as the way in which Twitter is "explained".

\section{Technological Innovations for 2011 Annual Meeting AERA Program App and Twitter}

As part of AERA's continued effort to improve the delivery and usability of the Annual Meeting Program, the Association is introducing two new electronic communications features this spring: a mobile application (app) and Twitter.

The complete program for registered attendees is featured in electronic and searchable format as the 2011 AERAAnnual Meeting Program app, for handheld personal digital assistant (PDA) units such as iPhones, iPads, Blackberries, and smart phones running on the Droid platform. Key functions of the app, supported by Core-Apps, include: Exhibitors, Sessions, Speakers, Social Media, Maps, and a Dashboard that allows attendees to create a personalized schedule. Registrants can download the free app to their mobile device by pointing their mobile browser to http://www.aera.net/mobileapp.htm. Registrants may also access the app on their personal computers via that same URL.

In addition, education researchers can share comments in 140 characters or less about sessions, new research, special events, and much more via the Association's Twitter account at www.twitter.com/AERA_EdResearch). Sign up online to join this realtime information network and participate in the streaming conversations.

Figure 6: Extract from AERA Conference Programme (AERA 2011, p. 5)

Neither then is presented as a mainstream technology. The introduction to Twitter is curious: why give a URL and invitation to "sign up"? Neither of us would think of "signing up" to participate in a Twitter exchange. However, the appeal to join a "real-time information network and participate in the streaming conversations" is a concisely descriptive invitation that might be experienced as persuasive to those who have become aware of Twitter through media discourses but not yet felt supported to start using the tool. The word "join" is particularly interesting, with its communitarian association. 
After AERA in 2011, Twitter communications were recorded and made the subject of research just as other conference-associated discourses, in other words deemed worthy of archiving rather than dismissed as ephemeral. For example Conley (2011) collected and summarised the \#AERA2011 tweets, identifying 1292 such tweets, constituted by $77.8 \%$ original and 22.2\% retweets. Although 291 separate twitter identities used the hashtag, most tweeted just once. Conley records that the most popular retweet was: "Two thirds of variability in student achievement comes from factors OUTSIDE school, researchers remind us" (originally tweeted by @BethFertig).

At the risk of moving beyond our autoethnographic framework here, we make the point from our own experiences that the institutionalisation of specific communicative tools may have a range of effects not necessarily envisaged. In reviewing our sense of prominent purposes for Twitter at the end of the year's study, we felt that it had undergone an interesting bifurcation. Simultaneously, we were aware of both an increasing appropriation by institutional and commercial interests on the one hand; and at the same time a replacement of mentions in mainstream British media discourses of the relatively highbrow celebrity Stephen Fry, a middle-aged broadcaster and writer as the prototypical famous tweeter by the emergence of Lady Gaga, a young pop singer. Such a bifurcation is familiar from other studies of Web 2.0 environments, as their increasing popularisation is matched both by intensifying commercial enterprises and a new abundance of unpaid labour (Ritzer \& Jurgenson, 2010). 


\section{Conclusions}

Communication is not a choice among a repertoire of fixed choices made available through a specific language code but rather an unfixable constantly mutating act of partial intersubjectivity. To participate in Twitter is to enter into a discursive relationship with others and to expect, to paraphrase Bakhtin, response, agreement, disagreement and more. One is not the first speaker "the one who disturbs the eternal silence of the universe" but the producer of an utterance which is "a link in a very complexly organised chain of other utterances..." (Bakhtin, 1986, p.69).

In his essay The Problem of Speech Genres Bakhtin argues that academic writing which is comprised of "various scientific and artistic genres" contributes to an ongoing conversation in much the same way as the real-life dialogue of speech communication. From this point of view, the text you are now reading - an utterance or work in the Bakhtin's terms - is produced in relation to prior utterances or works and anticipates a diverse range of responses. And in the Twitter environment, the flexibility of tweets, the ways in which readers can organise them to contribute to a flow of discourse that suits their own purposes whether professional, political, entertainment-oriented or even vital to one's own wellbeing and security instantiates Bakhtin's insight:

The work, like the rejoinder in dialogue, is oriented toward the response of the other (others), toward his [sic] active responsive understanding, which can assume 33 
various forms: educational influence on the readers, persuasion of them, critical responses, influence on followers and successors, and so on. It can determine others' responsive positions under the complex conditions of speech communication in a particular cultural sphere. The work is a link in the chain of speech communion. (Bakhtin, 1986, p.75-76)

One of the most significant and distinctive contributions of Bakhtin's speech genres essay is the way in which the differences between everyday communication and literary or scientific discourse are seen as a matter of degree rather than kind. In other words, the coconstruction of meaning through social interaction is a central feature of Bakhtin's understanding of language: it is a general principle that unites not only the everyday and the technical, but also one that transcends distinctions between speech and writing. How social interaction takes place, across channels and modes, all multimodal, is a key concern underlying this exploration and is as topical today - and to the world of Twitter (Marwick and boyd, 2011) - as it was in the early twentieth century.

Twitter, for us has become an exemplary mode of communication to study, instantiating so very clearly a dialogic understanding of communications processes.

For each word of the utterance that we are in the process of understanding, we, as it were, lay down a set of our own answering words... meaning is realised only in the process of active, responsive, understanding. (Volosinov, 1986, p. 102-103).

This insight can readily illuminate Web 2.0 practices in particular, in which meaningmaking can shift moment-by-moment between acts of "reading" and "writing" in digital 34 
literacy practices. We have endeavoured to show how attending to specific details of the material instantiation of the virtual contributes to a depth of understanding processes of deploying semiotic resources in meaning-making. This approach is explicitly different from studies that focus on the topics of texts analysed individually, or indeed more generalised descriptions that evade the grain of experience.

Thus, we hope to have contributed methodologically to the range of ways of researching new literacies using fast-evolving technologies. We would always seek to hold in mind the insight from Bazerman and Russell (2003, p. 1):

... to study text production, text reception, text meaning text value apart from their animating activities is to miss the core of text's being.

In this endeavour we have found an exploratory dual autoethnographic dialogue productive.

\section{References}

American Educational Research Association AERA, 2011. http://www.aera.net/uploadedFiles/Meetings_and_Events/2011_Annual_Meeting/Annual_Me eting_Program/ProgramCmteWeb.pdf accessed 13 May 2011.

Androutsopoulos, J., 2006. (Ed.) Special issue of the Journal of Sociolinguistics: Sociolinguistics and computer-mediated communication. 10 (4). 
Androutsopoulos, J., 2010. Localising the global on the participatory web: Vernacular spectacles as local responses to global media flows. In N. Coupland (Ed.) Handbook of Language and Globalization. Wiley-Blackwell, Oxford.

Androutsopoulos, J., 2011. From variation to heteroglossia in the study of computermediated discourse. In Thurlow, C., Mroczek, K. (Eds.), 2011. Digital Discourse: Language in the New Media. Oxford University Press, Oxford.

Arceneaux, N., Schmitz Weiss, A., 2010. Seems stupid until you try it: press coverage of Twitter, 2006-9. New Media \& Society 12 (8), 1262-1279.

Attia, A. M., Aziz, N., Friedman, B., Elhusseiny, M.F. 2011. Commentary: the impact of social networking tools on political change in Egypt's "Revolution 2.0". Electronic Commerce Research and Applications 10 (4), 369-374.

Bakhtin, M., (Ed. C. Emerson, M. Holquist), 1986. Speech Genres and Other Late Essays. University of Texas Press, Austin.

Barnes, S, and Böhringer, M. 2009. Continuance usage intention in microblogging services: the case of Twitter (Konferenzbeitrag). Proceedings of the 17th European Conference on Information Systems (ECIS).Verona, Italy June 8-10.

Baron, N., 2008. Always On: Language in an Online and Mobile World. Oxford University Press, New York.

Barton, D., 2007. Literacy: An Introduction to the Ecology of Written Language $2^{\text {nd }}$ ed.. Blackwell, Oxford 
Baym, N., 2010. Personal Connections in the Digital Age. Polity, Polity Press, Cambridge.

Bazerman, C., 1999. Letters and the social grounding of differentiated genres. In. D. Barton \& N. Hall (Eds.), Letter Writing as a Social Practice. John Benjamins, Amsterdam. Bazerman, C., Russell, D. 2003. Introduction. In: Bazerman, C., Russell, D. (Eds.), Writing Selves/Writing Societies. WAC Clearinghouse.

$<$ http://wac.colostate.edu/books/all.cfm>

Brown, G., Levinson, S. 1987. Politeness: Some Universals in Language Usage. Cambridge University Press, Cambridge

Conley, C., 2011. End of an AERA - AERA 2011 through the eyes of Twitter and R blog posting 12 April 2011. < http://cconley.ca/2011/04/12/end-of-an-aera-aera-2011through-the-eyes-of-twitter-and-r/>

Cottle, S., 2011. Media and the Arab uprisings 2011: research notes. Journalism: Theory, Practice \& Criticism, 12 (5), 647-659.

Crystal, D., 2001. Language and the Internet. Cambridge University Press, Cambridge. Danet, B., Herring, S.C. (Eds.), 2007. The Multilingual Internet: Language, Culture and Communication Online. Oxford University Press, New York.

Davies, J., Merchant, G., 2009. Web 2.0 for Schools: Learning and Social Participation. Peter Lang, New York. 
Davies, J., Merchant, G., 2007. Looking from the inside out: academic blogging as new literacy. In: Lankshear, C., Knobel, M. (Eds.), A New Literacies Sampler. Peter Lang, New York

Georgakopoulou, A. 2006. Postcript: computer-mediated communication in sociolinguistics. Journal of Sociolinguistics 10 (4), 548-557.

Gillen, J., 2011. The Edwardian Picture Postcard Project website. $<$ http://www.lancs.ac.uk/fass/projects/EVIIpc/>

Gillen, J., Hall, N., 2010. Edwardian postcards: Illuminating ordinary writing. In: Barton, D., Papen, U. (Eds.), The Anthropology of Writing. Continuum, London. Gillen, J., Merchant, G. (in press) From virtual histories to virtual literacies. In: Merchant, G, Gillen, J., Marsh. J., Davies, J. (Eds.), Virtual Literacies: Interactive Spaces for Children and Young People. Routledge, New York.

Green, J.L., Dixon, C.N., Zaharlick, A. 2003. Ethnography as a logic of inquiry. In: Flood, J., Lapp, D., Squire, J., Jensen, J. (Eds.), Handbook of Research on Teaching the English Language Arts 2nd ed., Erlbaum, Mahwah, NJ.

Gruzd, A., Wellman, B., Takhteyev, Y. 2011. Imagining Twitter as an imagined community. American Behavioral Scientist 5510 1294-1318

Hayles, N.K., 1999. How we Became Posthuman: Virtual Bodies in Cybernetics, Literature and Informatics. University of Chicago Press, Chicago.

Heath, S.B., 1983. Ways with Words. Cambridge University Press, London. 
Herring, S. C. (2004). Computer-mediated discourse analysis: An approach to researching online behavior. In: Barab, S.A., Kling, R., Gray, J.H. (Eds.), Designing for Virtual Communities in the Service of Learning. Cambridge University Press, New York.

Honeycutt, C., Herring, S.C., 2009. Beyond microblogging: conversation and collaboration via Twitter. Proceedings of the Forty-Second Hawai'I International Conference on System Sciences HICSS-42. IEEE Press, Los Alamitos, CA.

Iser, W., 1971. Indeterminacy and the reader's response to prose fiction. In: Miller, J.H., (Ed.), Aspects of Narrative. Columbia University Press, New York.

Java, A., Finin, T., Song., X \& Tseng, B. 2007. Why we Twitter: understanding microblogging usage and communities. Paper presented at the Joint $9^{\text {th }}$ WEBKDD and $1^{\text {st }}$ SNA-KDD Workshop '07, San Jose, CA. August 12.

Jones, J. \& Salter, L. 2011. Digital Journalism. Sage, London.

Kress, G., 2003. Literacy in the New Media Age. Routledge, New York.

Kress, G., 2010a. Multimodality: A Social Semiotic Approach to Contemporary Communication. Routledge, London.

Kress, G., 2010b. The profound shift of digital literacies. In: Gillen, J., Barton, D., (Eds.), Digital Literacies. Research briefing for the TLRP-TEL Teaching and Learning Research Programme - Technology Enhanced Learning. London Knowledge Lab, Institute of Education, London. <http://www.tlrp.org/docs/DigitalLiteracies.pdf>

Lankshear, C., Knobel, M., 2011. New Literacies: Everyday Practices and Classroom Learning $3^{\text {rd }}$ edn. Open University Press, Maidenhead. 
Lee, C. 2011. Micro-blogging and status updates on Facebook: texts and practices. In Thurlow, C., Mroczek, K. (Eds.), Digital Discourse: Language in the New Media. Oxford: Oxford University Press.

McCarthy, J. \& boyd, d., 2005. Digital backchannels in shared physical spaces: experiences at an academic conference. Conference on Human Factors and Computing Systems (CHI 2005). Portland, Oregon, USA, April 2-7. < http://www.danah.org/papers/>

McGonigal, J. 2011. Reality is Broken: Why Games make us Better and How they can Change the World. London: Penguin Books.

Marwick, A., boyd, D., 2011. I tweet honestly, I tweet passionately: Twitter users, context collapse, and the imagined audience. New Media \& Society 13 (1), 114-133.

Merchant, G. 2009. Web 2.0, new literacies and the idea of learning through participation. English Teaching, Practice and Critique 8 (3), 107-122.

Potts, L., Jones, D., 2011. Contextualizing experiences: tracing the relationships between people and technologies in the Social Web. Journal of Business and Technical Communication 253 338-358.

Ritzer, G., Jurgenson, N. 2010. Production, consumption, presumption: the nature of capitalism in the age of the digital "prosumer". Journal of Consumer Culture 10 (1), 13-36.

Rommetveit, R., 1992. Outlines of a dialogically based social-cognitive approach to human cognition and communication. In: Wold, A.H., (Ed.), The Dialogical Alternative: Towards a Theory of Language and Mind. Oxford University Press, Oxford.

Scollon, R., 2001. Mediated Discourse: The Nexus of Practice. Routledge, London. 40 
Sheller, M., 2004. Mobile publics: beyond the network perspective. Environment \& Planning D: Society \& Space 22 39-52.

Street, B., 1984. Literacy in Theory and Practice. Cambridge University Press, Cambridge.

Stevenson, R.L., [1879]2008. The story of a Lie, (Ed. D.J. Taylor). Hesperus Press, London.

Thurlow, C., Mroczek, K. (Eds.). 2011a. Digital Discourse: Language in the New Media. Oxford: Oxford University Press.

Thurlow C., Mroczek, K. 2011b. Introduction: fresh perspectives on new media sociolinguistics. In: Thurlow, C., Mroczek, K. (Eds.), 2011. Digital Discourse: Language in the New Media. Oxford University Press, Oxford.

Turkle, S., 2011. Alone together: how we expect more from technology and less from each other. New York: Basic Books.

Volosinov, V.N., 1995. "Language, speech, and utterance" and "verbal interaction". In: Dentith, S., (Ed.), Bakhtinian Thought: a Reader. Routledge, London.

Volosinov, V.N., 1986. Marxism and the Philosophy of Language. Harvard University Press, Cambridge, MA.

Wellman, B., 2001. The rise of networked individualism. In: Keeble, L., (Ed.), Community Networks Online. Taylor \& Francis, London.

Zappavigna, M., 2011. Ambient affiliation: A linguistic perspective on Twitter. New Media \& Society 135.

41 
Zappavigna, M. 2012. Discourse of Twitter and Social Media: How We Use Language to Create Affiliation on the Web. London: Continuum.

${ }^{1}$ Tweets are often ephemeral in the sense that their relevance and appearance on screen are short-lived. However, as we shall see, they are retrievable and, particularly of late, have become evidence in legal proceedings and media reports. There are some parallels here with descriptions of the ephemeral nature of spoken interactions. 
${ }^{2}$ Owing to the length of time the word "new" has been used, Literacy Studies is sometimes preferred.

${ }^{3}$ See Baron, 2008 and Turkle, 2011 for influential, more cautionary views of the impact of these technologies on society that discuss issues beyond the scope of this paper.

4 'Keying' must be seen as shorthand for the various ways of producing a tweet that include not only the mechanical press of keystrokes on a desktop computer but also the equivalent procedures on more portable devices (such as i-Pads and mobile phones) where the shimmer of electro-magnetic pulses on a touchscreen compose the tweet from a simulacrum of a keyboard.

${ }^{5}$ In each of the instances where specific twitter identities are mentioned we have contacted the person for permission to reproduce the quote. The exceptions are @bethfertig and @aggerscricket whose tweet identities show them as journalists with tweeting as part of their professional activity.

${ }^{6}$ This is a term used in social media to describe the ways in which one is simultaneously alone, but aware of, or in contact with friends (see McGonigal, 2011) 